\title{
Estimation of Fetal Weight by Ultrasonic Measurement of Several Fetal Growth Parameters
}

\author{
Akira Sato, Sheue-mei Liou, Yu Yamaguchi, Masumi \\ Sato and Masakuni Suzuki \\ Department of Obstetrics and Gynecology, Tohoku \\ University School of Medicine, Sendai 980
}

\begin{abstract}
Sato, A., Liou, S., Yamaguchi, Y., Sato, M. and Suzki, M. Estimation of Fetal Weight by Ultrasonic Measurement of Several Fetal Growth Parameters. Tohoku J. exp. Med., 1985, 146 (3), 349-361— Fetal biparietal diameter (BPD) and head, chest and abdominal circumferences (HC, CC, AC) were measured by means of real-time B-scan echography. The study population consisted of 198 patients who were hospitalized at Tohoku University Hospital. All live-born infants were delivered within $48 \mathrm{hr}$ after ultrasonic examination. This study was intended to establish criteria for diagnosis of fetuses weighing more than $2,500 \mathrm{~g}$ by means of a single ultrasonic measurement of several different fetal growth parameters. When estimated diameter of BPD exceeded $9.0 \mathrm{~cm}, 96.1 \%$ of the infants weighed more than 2,500 g. In all cases in which $\mathrm{HC}, \mathrm{CC}$ and $\mathrm{AC}$ exceeded $30 \mathrm{~cm}$, the infants weighed more than $2,500 \mathrm{~g}$. Finally, a multiple regression equation was constructed for estimation of birth weight by the values of fetal BPD, HC, CC and AC. The prediction error between prospective birth weight given by this formula and actual birth weight was $\pm 200 \mathrm{~g}$. The present method for estimation of fetal weight is simple and useful in obstetrical clinic._ultrasonic measurement; biparietal diameter; head circumference; chest circumference ; abdominal circumference
\end{abstract}

The major advances that have occurred in ultrasonography have been technological, particularly with regard to real-time instrumentation. The use of real-time ultrasonography in obstetrics has increased rapidly in the last decade. Although the utilization of ultrasonography in obstetrics has been based on the confirmation of pregnancy, estimation of gestational age, diagnosis of placenta previa, detection of congenital malformation, observation of fetal behavior and condition, and many other purposes, the most essential use in obstetrics is the evaluation of normal fetal growth and detection of intrauterine growth retardation (IUGR). The representative parameters for fetal growth are diameter of gestational sac and crown-lump length in the first trimester, and biparietal

Received January 23, 1985; accepted for publication March 14, 1985.

Reprint: Sato, A., Department of Obstetrics and Gynecology, Tohoku University School of Medicine, 1-1 Seiryo-machi, Sendai 980. 
diameter (BPD) and femur length (FL) in the second and third trimesters. These parameters are very significant when measured serially during pregnancy. However, it is usually difficult to measure these parameters consistently for out-patients. This study is intended to establish criteria for diagnosis of fetuses weighing more than $2,500 \mathrm{~g}$ with a single measurement, and to give a formula of estimation of fetal weight from several parameters measured by ultrasonography.

\section{Materials and Methods}

\section{Instruments}

All the measurements of biparietal diameter (BPD), head circumference (HC), chest circumference $(\mathrm{CC})$ and abdominal circumference $(\mathrm{AC})$ were performed with real-time B-scanners; U-Sonic RT-100 and 2000 (Yokogawa Medical System Co.) and Sonovista-P (Mochida Co.), all of them being equipped with transducers of $3.5 \mathrm{MHz}$ in frequency. The ultrasonic velocity was set at $1,540 \mathrm{~m} / \mathrm{sec}$ for the scanners except for the Sonovista-P which was set at $1,500 \mathrm{~m} / \mathrm{sec}$.

\section{Measurement procedure}

Biparietal diameter. Multiple scans were performed at the right angle to longitudinal axis of a fetus until a picture was obtained of an elliptic-shaped skull as well as the cavum septum pellucidum anteriorly and the falx cerebri posteriorly located in the midline of the profile. Using an electronic caliper, BPD was determined as a length from the outer edge of the anterior skull wall to the inner table of the posterior skull (Fig. 1).

Head circumference. The plane for HC measurement was the same as the plane for BPD measurement. Assuming a shape of a fetal head to be an ellipse, head circumference was calculated using the formula for an ellipse.

$$
\mathrm{HC}=\frac{\mathrm{BPD}+\text { occipito-frontal diameter }}{2} \times \pi(\text { Fig. } 1)
$$

Chest circumference. First, a longitudinal B-mode ultrasonogram of a sagittal section of a fetus was obtained. Fetal spine was then located. Subsequently, the transverse section at the right angle to the spine immediately caudal to the heart pulsations was obtained and could be demonstrated on a transverse section. At this level, the fetal spine,

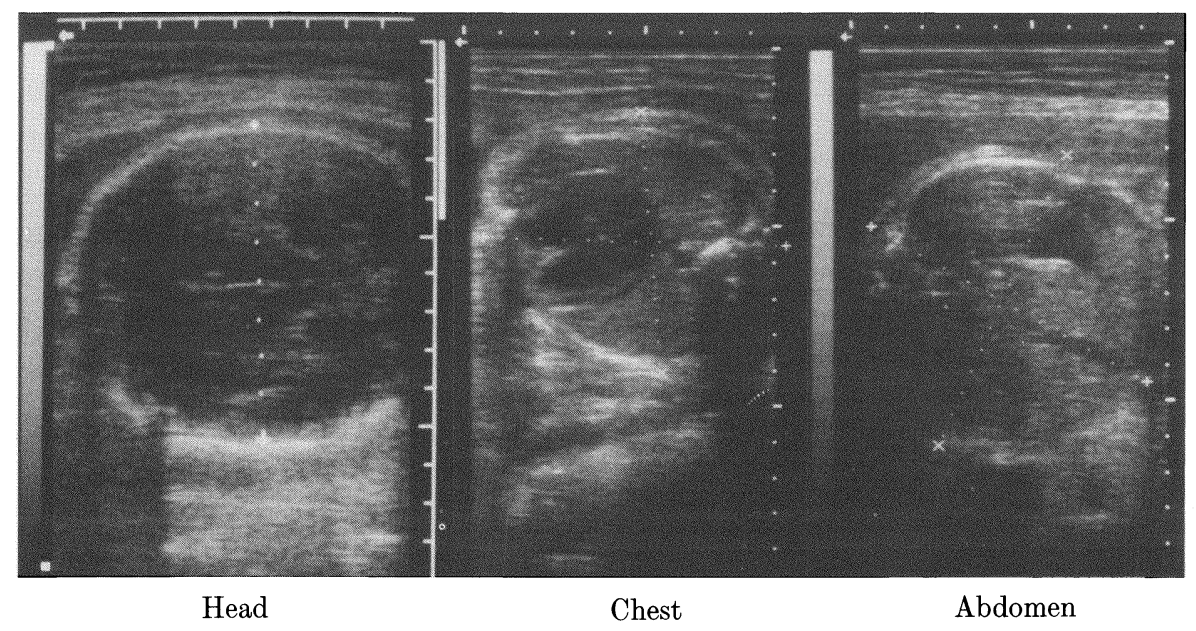

Fig. 1. Representative photographs of fetal head, chest and abdomen. 


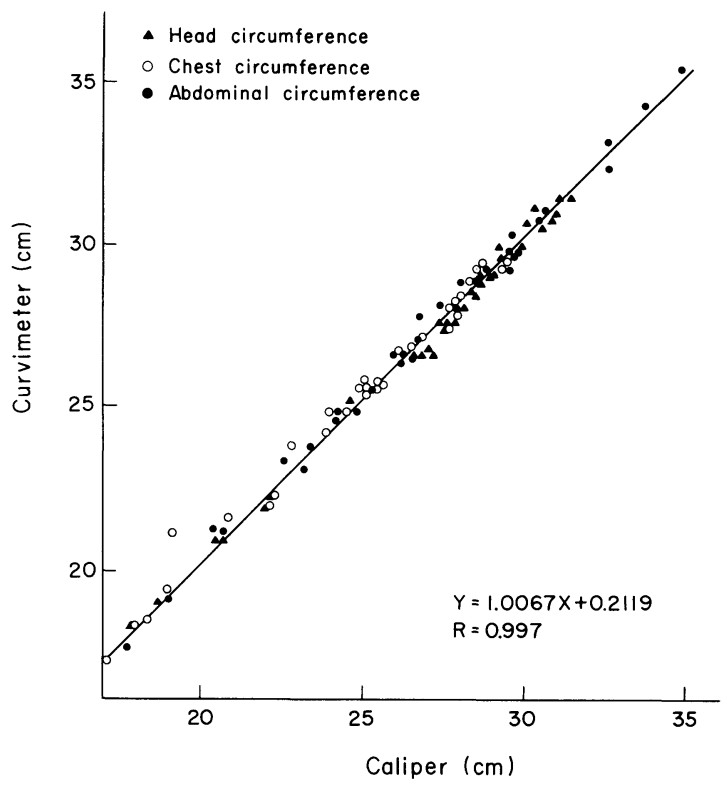

Fig. 2. Correlation between the circumference value obtained from diameter caliper and curvimeter. Measurements by ellipic approximation ("Caliper") and that measured directly with a curvimeter ("Curvimeter").

heart, and liver can always be visualized. The transverse and the anteroposterior diameter of fetal chest were then measured with an electronic caliper. A fetal chest circumference was caluculated as well as BPD (Fig. 1).

Abdominal circumference. Ultrasonic real-time B-scans were first made at different angles to the midline of the maternal abdomen to identify the position of a long axis of a fetal body. Where there was marked flexion of a fetal body, it was helpful to identify a significant length of the fetal aorta or fetal dorsal spine. Scans were then made orthogonal to the long axis of the fetal body and a section across the upper abdomen was selected. This plane was recognized by the typical appearance of the umbilical vein as it passed under the fetal liver. Usually the umbilical vein could be easily confirmed. Under this section, we have sometimes found the fetal stomach. This method of abdominal circumference measurement is the same as that described by Campbell and Wilkin (1975). The calculation of abdominal circumference was performed in the same way as head and chest circumferences (Fig. 1).

In order to evaluate the present measurement process by the elliptic approximation, each circumference was measured on a polaroid photograph by a curvimeter. After that, each circumference was calculated with reduced scale. The correlation between the value obtained from the formula of elliptic approximation by a caliper and the value determined by a curvimeter is as follows :

$Y=1.0067 X+0.2119$

$Y=$ value of $\mathrm{AC}$ by using a curvimeter,

$X=$ value of AC by using the formula of elliptic approximation by caliper.

Correlation coefficient $r=0.997$.

There was a good correlation between the value using a caliper and the value using a curvimeter (Fig. 2). From this result, the present measurement method was considered reliable. 


\section{Patients}

The study population consisted of 198 patients who were hospitalized at Tohoku University Hospital. The live-born infants consisted of 172 appropriate-for-gestational-age (AGA) infants and 26 small-for-gestational-age (SGA) infants, and they were classified according to definition previously reported (Sato et al. 1982). The fetal growth parameters were measured in all the live-born cases delivered within $48 \mathrm{hr}$ after the latest ultrasonic examination. Data processing and statistical analysis were carried out at Tohoku University Computer Center.

\section{RESULTS}

\section{Correlation between BPD and birth weight}

There was a good correlation between BPD and birth weight in cases in which $\mathrm{BPD}$ was 8 to $10 \mathrm{~cm}$. Coefficient of correlation was 0.769 and the regression line between these two factors was expressed by an equation as follows:

$$
Y=854.8 X-4911.9
$$

where $Y$ is birth weight in grams and $X$ is BPD in $\mathrm{cm}$ (Fig. 3). In $89 \%$ of the

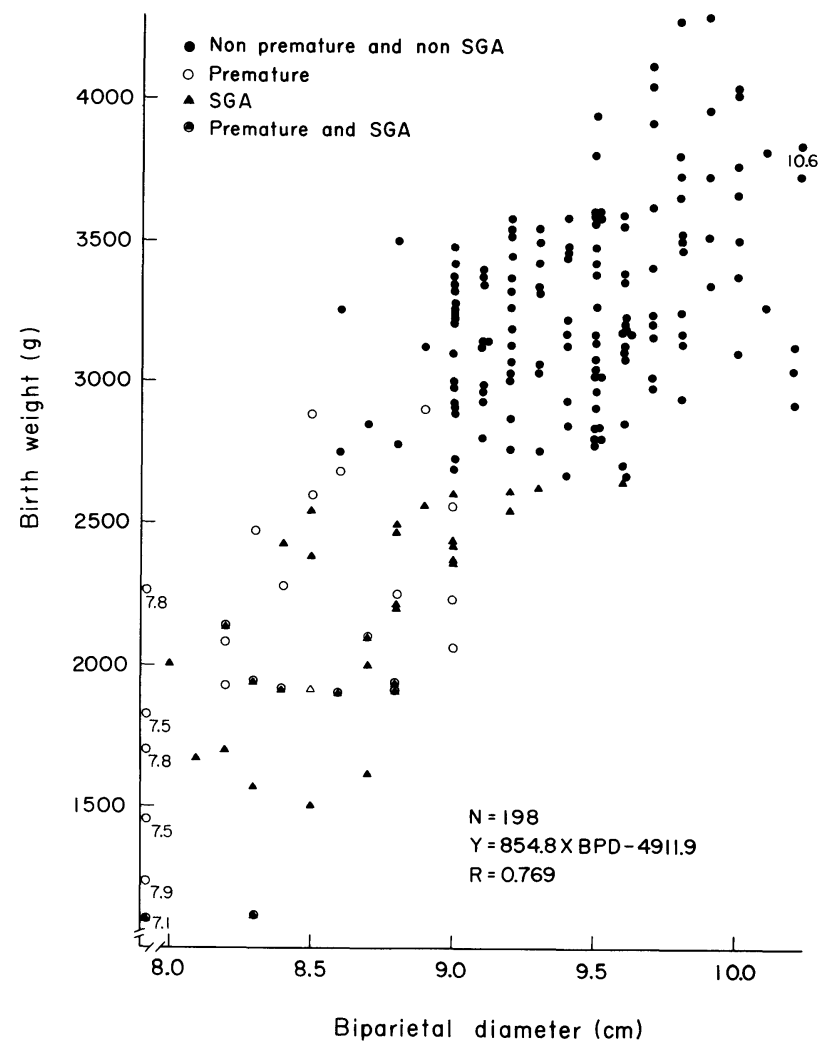

Fig. 3. Correlation between BPD and birth weight, in 198 cases devided into four categories as indicated in the figure. "Premature" means infants whose gestational age $\leqq 36$ weeks and "SGA" was defined as described in the text. 
TABLE 1. Correlation between measurements of biparietal diameter (BPD) and birth weight exceeding $2500 \mathrm{~g}$

\begin{tabular}{|c|c|c|c|c|}
\hline $\mathrm{BPD}(\mathrm{cm})$ & $\begin{array}{c}<2500 \mathrm{~g} \\
\text { cases }\end{array}$ & $\begin{array}{c}\geqq 2500 \mathrm{~g} \\
\text { cases }\end{array}$ & $\begin{array}{l}\text { Accumula } \\
\text { for infants } \\
\text { more thar }\end{array}$ & $\begin{array}{l}\text { tion rate } \\
\text { weighing } \\
2500 \mathrm{~g}\end{array}$ \\
\hline $8.0>$ & 6 & & & \\
\hline 8.0 & 1 & & & \\
\hline 8.1 & 1 & & & \\
\hline 8.2 & 4 & & & \\
\hline 8.3 & 4 & & & \\
\hline 8.4 & 3 & & & \\
\hline 8.5 & 3 & 2 & $159 / 179$ & $88.8 \%$ \\
\hline 8.6 & 1 & 4 & $157 / 174$ & $90.2 \%$ \\
\hline 8.7 & 3 & 1 & $153 / 169$ & $90.5 \%$ \\
\hline 8.8 & 7 & 2 & $152 / 165$ & $92.1 \%$ \\
\hline 8.9 & & 3 & $150 / 156$ & $96.1 \%$ \\
\hline 9.0 & 6 & 21 & $147 / 153$ & $96.1 \%$ \\
\hline 9.1 & & 10 & $126 / 126$ & $100 \%$ \\
\hline 9.2 & & 17 & & \\
\hline 9.3 & & 10 & & \\
\hline 9.4 & & 9 & & \\
\hline 9.5 & & 24 & & \\
\hline 9.6 & & 16 & & \\
\hline 9.7 & & 10 & & \\
\hline 9.8 & & 11 & & \\
\hline 9.9 & & 5 & & \\
\hline 10.0 & & 7 & & \\
\hline $10.0<$ & & 7 & & \\
\hline Total & 39 & 159 & & \\
\hline
\end{tabular}

cases in which BPD was above $8.5 \mathrm{~cm}$, the birth weight exceeded $2,500 \mathrm{~g}$, and in $96.1 \%$ of the cases with BPD above $9.0 \mathrm{~cm}$, the birth weight was more than 2,500 g (Table 1).

Correlation between birth weight and $H C$

The regression line between birth weight and $\mathrm{HC}$ was expressed by an equation : $Y=286.4 X-5717.6$,

where $Y$ is birth weight and $X$ is HC. Coefficient of correlation $(r)$ was 0.789 . There was a good correlation between these two factors in the AGA cases. But there was no significant correlation in the SGA cases (Fig. 4).

In all cases in which $\mathrm{HC}$ was below $26 \mathrm{~cm}$, the infants weighed less than 2,500 g. In all cases in which $\mathrm{HC}$ exceeded $30 \mathrm{~cm}$ these infants weighed more than $2,500 \mathrm{~g}$. 


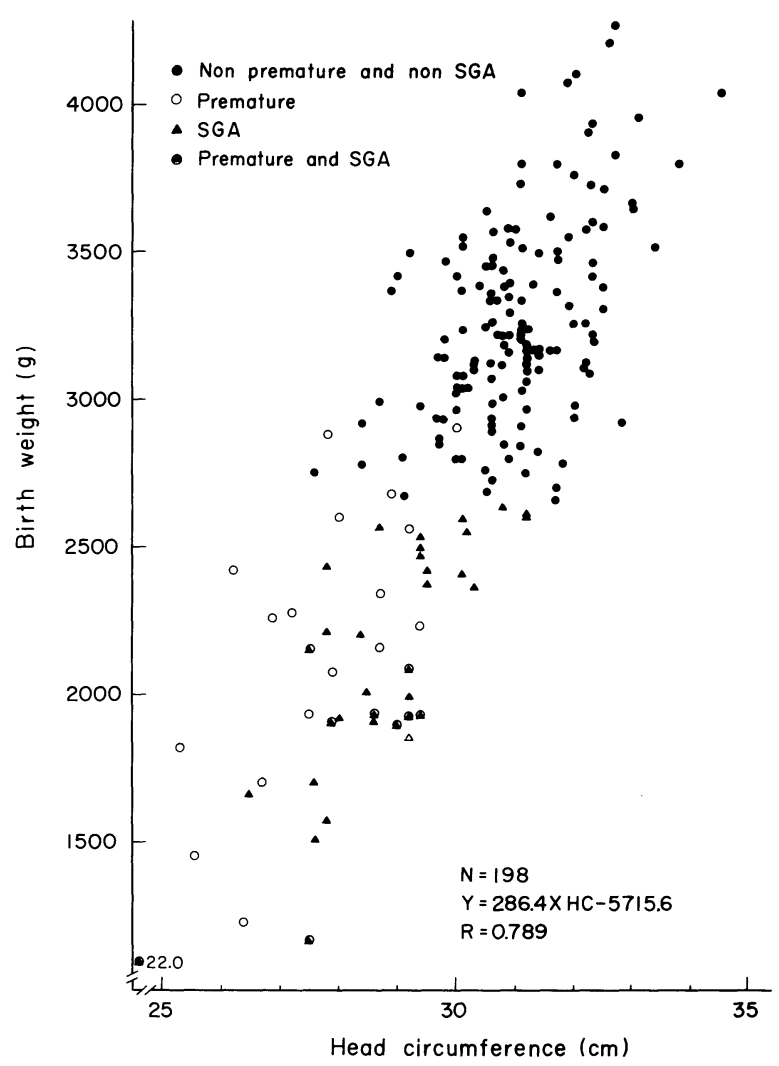

Fig. 4. Correlation between head circumference and birth weight. Categorization and symbols are as in Fig. 3 .

Correlation between birth weight and $C C$

The regression line between birth weight and $\mathrm{CC}$ was expressed by a following equation:

$$
Y=200.5 X-2852.6
$$

where $Y$ is birth weight and $X$ is CC.

Coefficient of correlation ( $r$ ) was 0.887 (Fig. 5).

In all cases in which $\mathrm{HC}$ exceeded $30 \mathrm{~cm}$, the infants weighed more than 2,500 g (Table 3).

Correlation between birth weight and $A C$

There was a good correlation between birth weight and AC. Coefficient of correlation was 0.891 . The regression line between these two factors was expressed by a following equation :

$$
Y=208.7 X-3409.5
$$

where $Y$ is the birth weight and $X$ is AC (Fig. 6). In all cases in which AC was 
TABLE 2. Correlation between measurements of head circumference (HC) and birth weight exceeding $2500 \mathrm{~g}$

\begin{tabular}{|c|c|c|c|c|}
\hline \multirow{2}{*}{$\begin{array}{c}\mathrm{HC}(\mathrm{cm}) \\
20\end{array}$} & \multirow[t]{2}{*}{$\begin{array}{c}<2500 \mathrm{~g} \\
\text { cases }\end{array}$} & \multirow[t]{2}{*}{$\begin{array}{l}\geqq 2500 \mathrm{~g} \\
\text { cases }\end{array}$} & \multicolumn{2}{|c|}{$\begin{array}{l}\text { Accumulation rate } \\
\text { for infants weighing } \\
\text { more than } 2500 \mathrm{~g}\end{array}$} \\
\hline & & & & \\
\hline 21 & 1 & & & \\
\hline \multicolumn{5}{|l|}{22} \\
\hline \multicolumn{5}{|l|}{23} \\
\hline 24 & 2 & & & \\
\hline 25 & 5 & & & \\
\hline 26 & 11 & 2 & $159 / 190$ & $83.7 \%$ \\
\hline 27 & 7 & 7 & $157 / 177$ & $88.7 \%$ \\
\hline 28 & 11 & 15 & $150 / 163$ & $92.0 \%$ \\
\hline 29 & 2 & 60 & $135 / 137$ & $98.5 \%$ \\
\hline 30 & & 43 & $75 / 75$ & $100 \%$ \\
\hline 31 & & 26 & & \\
\hline 32 & & 5 & & \\
\hline 33 & & 1 & & \\
\hline \multicolumn{5}{|l|}{34} \\
\hline \multicolumn{5}{|l|}{35} \\
\hline \multicolumn{5}{|l|}{36} \\
\hline Total & 39 & 159 & & \\
\hline
\end{tabular}

below $26 \mathrm{~cm}$, the infants weighed less than $2,500 \mathrm{~g}$. In all cases in which $\mathrm{AC}$ was greater than $30 \mathrm{~cm}$, the infants weighed more than $2,500 \mathrm{~g}$ (Table 4).

\section{Estimation of fetal body weight}

A multiple regression equation for estimation of birth weight by using values of $\mathrm{BPD}, \mathrm{HC}, \mathrm{CC}$ and $\mathrm{AC}$ measured by ultrasonography, fundal height of uterus, and gestational age was as follows:

$$
\begin{aligned}
& Y=47.227 X_{1}+103.939 X_{2}+63.848 X_{3}+105.109 X_{4}+9.082 X_{5} \\
& +49.228 X_{6}-7702.901 . \\
& X_{1}: \mathrm{BPD}, X_{2}: \mathrm{HC}, X_{3}: \mathrm{CC}, X_{4}: \mathrm{AC}, \\
& X_{5}: \text { gestational age (weeks) } \\
& X_{6}: \text { fundal height }(\mathrm{cm}) \\
& \text { Correlation coefficient }: r=0.943
\end{aligned}
$$

\section{Correlation between birth weight and estimated birth weight}

Prospective study of 122 cases was done by using the equation for estimating birth weight. There was an excellent correlation between actual birth weight and the estimated birth weight (correlation coefficient: $r=0.943$ ). Prediction error 


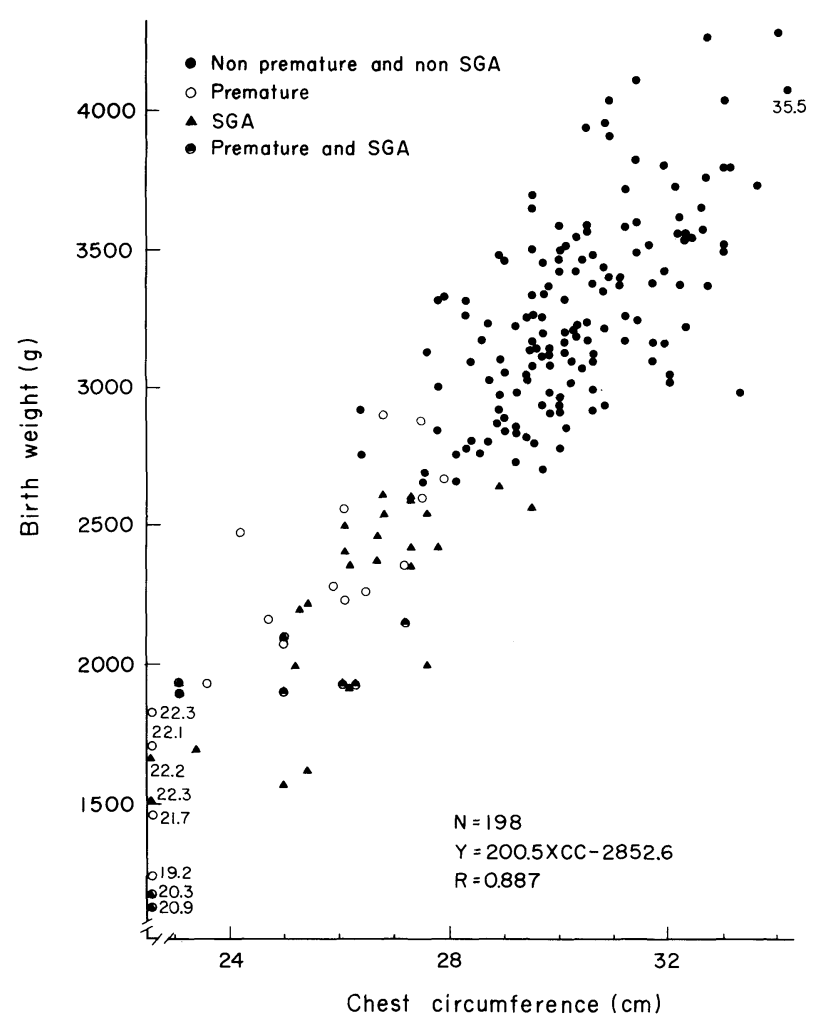

Fig. 5. Correlation between chest circumference and birth weight. Categorization and symbols are as in Fig. 3 .

was \pm 200 g (Fig. 7).

\section{Discussion}

Recently, several authors have attempted to evaluated fetal growth by ultrasonic measurement of a number of different fetal growth parameters (Thompson et al. 1965; Hellman et al. 1967; Campbell 1968). These parameters have been used to detect IUGR. It has been shown in the infant with IUGR that there is a 3 - to 8 -fold increase in perinatal mortality, markedly increased perinatal morbidity and many long-term problems in growth and development. It is, therefore, essential that such an IUGR fetus is recognized antenatally. Ultrasonography should provide an ideal means of detecting such a fetus. The purpose of this study was to detect a fetus weighing more than $2,500 \mathrm{~g}$ by a simple ultrasonic measurement. Finally, a formula was proposed for estimation of fetal weight by means of ultrasonic measurements of $\mathrm{BPD}, \mathrm{HC}, \mathrm{CC}$ and $\mathrm{AC}$.

Kohorn (1967) reported that neonatal weight exceeded $2,500 \mathrm{~g}$ in $96 \%$ of the patients studied, if estimated BPD exceeded $8.5 \mathrm{~cm}$. Thompson et al. (1965) reported that in $91 \%$ of the infants in which $\mathrm{BPD}$ was $8.5 \mathrm{~cm}$ or greater, the fetal 
TABLE 3. Correlation between measurements of chest circumference (CC) and birth weight exceeding $2500 \mathrm{~g}$

\begin{tabular}{|c|c|c|c|c|}
\hline \multirow{2}{*}{$\begin{array}{c}\mathrm{CC}(\mathrm{cm}) \\
20>\end{array}$} & \multirow{2}{*}{$\begin{array}{c}<2500 \mathrm{~g} \\
\text { cases }\end{array}$} & \multirow[t]{2}{*}{$\begin{array}{l}\geqq 2500 \mathrm{~g} \\
\text { cases }\end{array}$} & \multicolumn{2}{|c|}{$\begin{array}{l}\text { Accumulation rate } \\
\text { for infants weighing } \\
\text { more than } 2500 \mathrm{~g}\end{array}$} \\
\hline & & & & \\
\hline 20 & 2 & & & \\
\hline 21 & 1 & & & \\
\hline 22 & 4 & & & \\
\hline 23 & 4 & & & \\
\hline 24 & 2 & & & \\
\hline 25 & 9 & & $159 / 184$ & $86.4 \%$ \\
\hline 26 & 10 & 6 & $159 / 175$ & $90.8 \%$ \\
\hline 27 & 6 & 13 & $153 / 159$ & $96.2 \%$ \\
\hline 28 & & 19 & $140 / 140$ & $100 \%$ \\
\hline 29 & & 37 & & \\
\hline 30 & & 41 & & \\
\hline 31 & & 20 & & \\
\hline 32 & & 13 & & \\
\hline 33 & & 7 & & \\
\hline 34 & & 2 & & \\
\hline 35 & & 1 & & \\
\hline Total & 39 & 159 & & \\
\hline
\end{tabular}

weight was in excess of $2,500 \mathrm{~g}$. When the estimated diameter exceeded $9.0 \mathrm{~cm}$, $97 \%$ of the babies weighed more than $2,500 \mathrm{~g}$. Nakazawa (1973) demonstrated that $95 \%$ of the babies weighed more than $2,500 \mathrm{~g}$ if their estimated diameter exceeded $8.5 \mathrm{~cm}$. From the present results, it was possible to demonstrate that in $89 \%$ of the patients studied, neonatal weight exceeded $2,500 \mathrm{~g}$ if estimated BPD exceeded $8.5 \mathrm{~cm}$. When the estimated diameter exceeded $9.0 \mathrm{~cm}, 96.1 \%$ of the neonates weighed more than $2,500 \mathrm{~g}$. This result was similar to Thompson's.

Campbell and Wilkin (1975) has reported that AC determined by ultrasonic measurement is useful for detecting fetal growth, and that a single measurement of fetal AC would also appear to be more efficient in diagnosing a small-for-dates fetus than serial cephalometry and has a lower incidence of false positive diagnosis. They also demonstrated that neonatal birth weight was in excess of $2,500 \mathrm{~g}$ if an estimated AC was $29.0-32.0 \mathrm{~cm}$. From the present results, it was possible to estimate fetal weight heavier than $2,500 \mathrm{~g}$ at a success rate of $100 \%$, if $\mathrm{AC}$ from ultrasonic measurement was $30 \mathrm{~cm}$ or greater. The difference between our results and Campbell's may be due to the difference in calculating AC. Campbell and Wilkins (1975) stated that circumference measurements were made on a polaroid photograph by means of a map measurer with appropriate correction for picture 


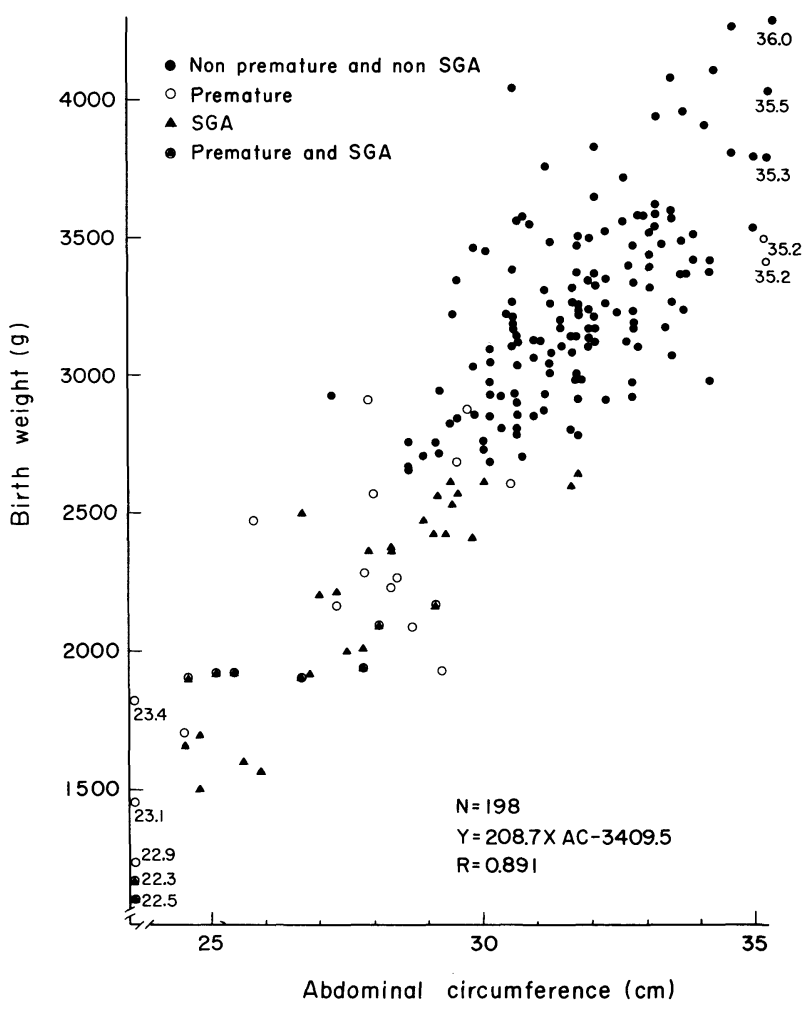

Fig. 6. Correlation between abdominal circumference and birth weight. Categorization and symbols are as in Fig. 8.

size. We measured long and short diameters of the abdomen on the same plane as in Campbell's method, and calculated AC from the data as an ellipse. Clinically, it is very complicated to measure $\mathrm{AC}$ on a polaroid photograph consistently. Our calculation is simple and more useful than Campbell's method.

There are a few reports concerning the correlation between birth weight of an infant and ultrasonic measurement of fetal HC and CC (Thompson et al. 1965; Issel and Prenzlau 1974). The reason for this is thought to be that an anteroposterior diameter of the head cannot be measured accurately because a contour line of the head cannot be clearly identified on a screen. Another reason is that CC cannot be measured accurately because it is very difficult to obtain constantly the same chest section. It is thought, however, that this difficulty may be dissolved by practice.

A number of authors have attempted to estimate fetal weight by ultrasonic measurement of a number of different fetal growth parameters (Higginbotton et al. 1975 ; Lunt and Chard 1976; Warsof et al. 1977). Willocks and associates (1964) reported that estimation of birth weight by BPD alone had standard deviation of a prediction error $\pm 350.36 \mathrm{~g}$ and correlation coefficient was 0.77. From our 
TABLE 4. Correlation between measurements of abdominal circumference (AC) and birth weight exceeding $2500 \mathrm{~g}$

\begin{tabular}{|c|c|c|c|c|}
\hline \multirow{2}{*}{$\begin{array}{c}\mathrm{AC}(\mathrm{cm}) \\
20\end{array}$} & \multirow[t]{2}{*}{$\begin{array}{l}<2500 \mathrm{~g} \\
\text { cases }\end{array}$} & \multirow[t]{2}{*}{$\begin{array}{c}\geqq 2500 \mathrm{~g} \\
\text { cases }\end{array}$} & \multicolumn{2}{|c|}{$\begin{array}{l}\text { Accumulation rate } \\
\text { for infants weighing } \\
\text { more than } 2500 \mathrm{~g}\end{array}$} \\
\hline & & & & \\
\hline 21 & & & & \\
\hline 22 & 3 & & & \\
\hline 23 & 2 & & & \\
\hline 24 & 4 & & & \\
\hline 25 & 5 & & & \\
\hline 26 & 3 & & $159 / 184$ & $86.4 \%$ \\
\hline 27 & 9 & 2 & $159 / 181$ & $87.8 \%$ \\
\hline 28 & 7 & 6 & $157 / 170$ & $92.4 \%$ \\
\hline 29 & 6 & 16 & $151 / 157$ & $96.2 \%$ \\
\hline 30 & & 35 & $135 / 135$ & $100 \%$ \\
\hline 31 & & 37 & & \\
\hline 32 & & 26 & & \\
\hline 33 & & 22 & & \\
\hline 34 & & 10 & & \\
\hline 35 & & 4 & & \\
\hline 36 & & 1 & & \\
\hline Total & 39 & 159 & & \\
\hline
\end{tabular}

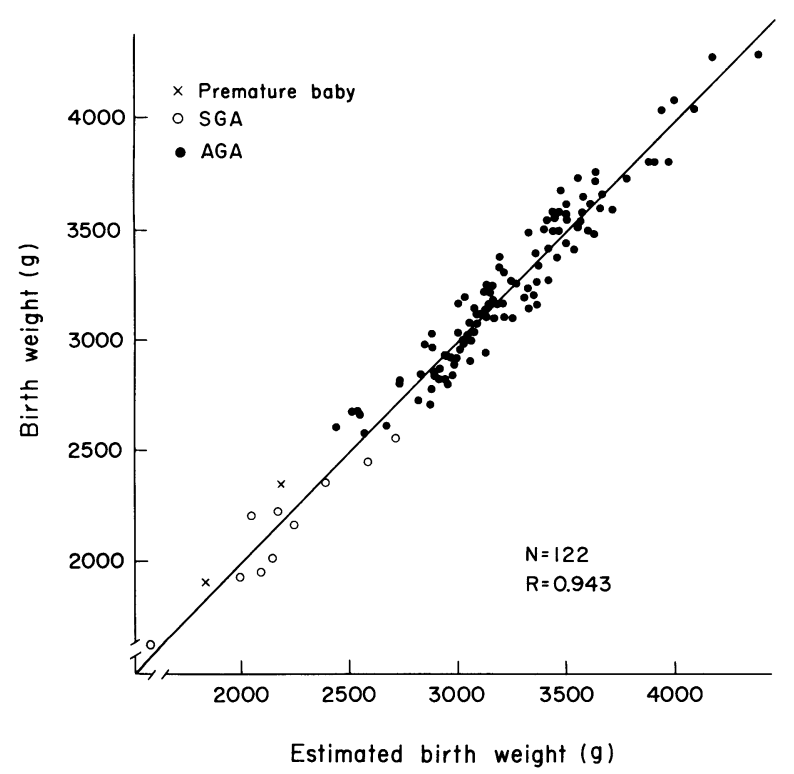

Fig. 7. Correlation between birth weight and estimated birth weight. $\bullet$, non premature and non SGA infants ; $\times$, premature infants; $O$, SGA infants. 
results, correlation coefficient was also 0.77 using $\mathrm{BPD}$ alone. However, the correlation between these parameters is not sufficiently reliable to be of a clinical value.

Campbell and Wilkin (1975) gave a formula for estimating birth weight using ultrasonic measurement of AC. From their results, the error was \pm 9.1 percent. Thompson and Makowski (1971) measured both biparietal and anteroposterior chest in newborn infants and made an equation to predict birth weight from these two parameters. They found that estimated birth weight had a standard deviation of $290 \mathrm{~g}$, which was less than that obtained from either diameter alone. Since this report, a number of authors have attempted to estimate fetal weight using ultrasonic measurement of several fetal growth parameters (Suzuki et al. 1974 ; Picker and Saunders 1976; Wladimiroff et al. 1977). Minoura et al. (1976) gave a multiple regression equation for estimation of birth weight using maternal age, parity, maternal height, gestational age fundal height, circumference of maternal abdomen, maternal weight and fetal BPD. From their results, their prediction error had standard deviation of $250 \mathrm{~g}$. In this study, we constructed a multiple regression equation for estimation of birth weight using values of fundal height, gestational age, and fetal $\mathrm{BPD}, \mathrm{HC}, \mathrm{CC}$ and $\mathrm{AC}$ which were measured by real-time ultrasonography. In the prospective study using these formula, prediction error was $\pm 200 \mathrm{~g}$. Our method for estimation of fetal weight is simple and we believe it will be useful in obstetric practice.

\section{References}

1) Campbell, M.B. (1968) An improved method of fetal cephalometry by ultrasound. Brit. J. Obstet. Gynaec., 75, 568.

2) Campbell, S. \& Wilkin, D. (1975) Ultrasound measurement of fetal abdominal circumference in estimation of fetal weight. Brit. J. Obstet. Gynaec., 82, 689-697.

3) Hellman, L.M., Kobayashi, M., Fillisti, L., Lavenhar, M. \& Cromb, E. (1967) Sources of error in sonographic fetal mensuration and estimation of growth. Amer. J. Obstet. Gynec., 99, 662-670.

4) Higginbotton, J., Slater, J., Porter, G. \& Whitfield, C.R. (1975) Estimation of fetal weight from ultrasonic measurement of trunk circumference. Brit. J. Obstet. Gynaec., 82, 698-701.

5) Issel, E.P. \& Prenzlau, P. (1974) Eine neue Methode zur Berechung des fetalen Gewichtes mittels ultraschll-B-bild-Technik'. Zbl. Gynäk., 96, 417-429.

6) Kohorn, E.T. (1967) An evaluation of ultrasonic fetal cephalometry. Amer. J. Obstet. Gynec., 97, 553-559.

7) Lunt, R. \& Chard, T. (1976) A new method for estimation of fetal weight in late pregnancy by ultrasonic scanning. Brit. J. Obstet. Gynaec., 83, 1-5.

8) Minoura, S., Hara, K., Kubo, T., Hogaki, M. \& Sakamoto, S. (1976) In : Prediction of the 29th Meeting of the Japanese Society of Ultrasonics in Medicine, p. 139. (Japanese with English abstract)

9) Nakazawa, T. (1973) Studies on assessment of fetal growth by ultrasound fetal cephalometry. Nippon Sanka-Fujinka Gakkai Zasshi, 25, 873-882. (Japanese)

10) Picker, R. \& Saunders, D. (1976) A simple geometric method for determining fetal weight in utero with compound gray scale ultrasound scan. Amer. J. Obstet. Gynec., 
124, 493-494.

11) Sato, A., Akama, M., Yamanobe, H., Hoshi, K. \& Suzuki, M. (1982) Intrauterine growth of live-born Japanese infants between 28 and 42 weeks of gestation. Acta obstet. gynaec. jap., 34, 1535-1538. (Japanese)

12) Suzuki, K., Minci, L.J. \& Schnitzer, L.E. (1974) Ultrasonic measurement of fetal heart volume for estimation of birth weight. Obstet. Gynecol., 43, 867-871.

13) Thompson, H.E. \& Makowski, E.L. (1971) Birth weight and gestational age. Obstet. Gynecol., 37, 44-47.

14) Thompson, H.E., Holmes, J.H., Gottesfeld, K.R. \& Taylor, E.S. (1965) Fetal development as determined by ultrasonic echo techniques. Amer. J. Obstet. Gynec., 92, 44-52.

15) Warsof, S.L., Gohari, R., Berkowitz, R.L. \& Hobbins, J.C. (1977) The estimation of fetal weight by computer-assisted analysis. Amer. J. Obstet. Gynec., 128, 881-892.

16) Willocks, J., Donald, I., Duggan, T.C. \& Day, N. (1964) Fetal cephalometry by ultrasound. Brit. J. Obstet. Gynaec., 71, 11-20.

17) Wladimiroff, J.W., Bloemsmd, G.A. \& Wallenburg, C.S. (1977) Ultrasonic assessment of fetal growth. Acta obstet. gynec. scand., 56, 37-42. 